\title{
Cam/ITO/CIS/Rubrene Heteroekleminin Yüzey ve Optiksel Özelliklerinin İncelenmesi
}

\author{
Fatih ÜNAL ${ }^{1 *}$, Tekin İZGİ², Behzad BARIŞ ${ }^{3}$, Serdar KARADENIZ ${ }^{4}$
}

\section{Öz}

$\mathrm{Bu}$ çalışmada, CuInSe (CIS) ince filmleri cam/ITO alttabakalar üzerine elektro-kimyasal kaplama yöntemi ile oluşturulmuştur. Cam/ITO/CIS filmlerinin yüzey morfolojilerinin ve optiksel özelliklerinin incelenebilmesi için AFM ve UV-VIS analizleri yapılmıştır. Analiz işlemleri bittikten sonra cam/ITO/CIS yapılarının üzerine termal buharlaştırma yöntemi ile rubrene $\left(\mathrm{C}_{42} \mathrm{H}_{28}\right)$ ince filmleri oda sıcaklığında ve $2,5 \times 10^{-6}$ torr basınç altında kaplanmıştır. Elde edilen cam/ITO/CIS/rubrene heteroeklemlerinin yüzey morfolojilerinin ve optiksel özelliklerinin incelenmesi için AFM ve UVVIS analizleri tekrar yapılmıştır. AFM analizleri sonucunda cam/ITO/CIS ve cam/ITO/CIS/rubrene yapılarının yüzey pürüzlülük değerleri sırasıyla; 231,6 nm ve 182,82 nm olarak belirlenmiştir. UV-VIS analizlerinde cam/ITO/CIS, ve cam/ITO/CIS/rubrene yapılarının yasak enerji aralıkları sırasıyla; 1,42 eV ve 2,07eV olarak belirlenmiştir.

Anahtar Kelimeler: İnce film, CuInSe (CIS), Rubrene.

\section{Investigation of Surface and Optical Properties of Glass/ITO/CIS/Rubrene Heterojunction}

\begin{abstract}
In this work, CuInSe (CIS) thin films were deposited on glass/ITO by electro-deposition technique. The surface microstructure, surface roughness and the band gap were analyzed using AFM and UV-VIS techniques for all glass/ITO/CIS structures. After these analyzing processes were completed, rubrene $\left(\mathrm{C}_{42} \mathrm{H}_{28}\right)$ thin film was coated on glass/ITO/CIS structures by using thermal evaporation method under $2,5 \times 10^{-6}$ torr at room temperature. Then, the analyzing processes of surface microstructure, surface roughness and the band gap were repeated. As a result of AFM analysis, surface roughness values of glass/ITO/CIS and glass/ITO/CIS/rubrene were found to be 231,6 nm and 182,82 $\mathrm{nm}$, respectively. As a result of UV-VIS analysis, the band gap values of glass/ITO/CIS and glass/ITO/CIS/rubrene structures were determined as $1,42 \mathrm{eV}$ and 2,07eV, respectively.
\end{abstract}

Keywords: Thin film, CuInSe (CIS), Rubrene.

\footnotetext{
${ }^{1}$ Giresun Üniversitesi, Merkezi Araştırma Laboratuvarı Uygulama ve Araştırma Merkezi, Giresun, Türkiye, fatih.unal@giresun.edu.tr ${ }^{2}$ İnönü Üniversitesi, Fizik Bölümü Fen Edebiyat Fakültesi, Malatya, Türkiye, tekin.izgi@inonu.edu.tr

${ }^{3}$ Giresun Üniversitesi, Fizik Bölümü Fen Edebiyat Fakültesi, Giresun, Türkiye, behzadbaris@yahoo.com

${ }^{4}$ Giresun Üniversitesi, Enerji Sistemleri Müh. Bölümü Mühendislik Fakültesi, Giresun, Türkiye, serdar.karadeniz@giresun.edu.tr
}

${ }^{1}$ https://orcid.org/0000-0002-6155-7051 ${ }^{4}$ https://orcid.org/0000-0002-1792-8134
${ }^{2}$ https://orcid.org/0000-0002-4489-905X

3https://orcid.org/0000-0003-3041-6413 


\section{Giriş}

Üçlü yarıiletken bileşik olan CuInSe (CIS), doğrudan bant aralığına, yüksek soğurma verimliliğine, foto-dejenerasyonuna karşı dirençli ve iyi bir termal kararlılığa sahip olmasından dolayı öncü yarıiletken bileşikler içerisinde yer almaktadır (Kashyout, 2014; Liu, Zhang, Lai, Li, \& Liu, 2009; Bari, 2006). CIS yapılar, düşük maliyetleri ile ince fillm güneş hücreleri arasında gelecek vadeden soğurucu materyaller olmasından dolayı öncü bileşiklerden biridir. Üretimi kolay ve üzerine gelen güneş 1şınlarını soğurabilme kapasitesi yüksek olan CIS, güneş hücreleri yapımında kullanılabilen en iyi bileşikler arasındadır (Kaleli, 2017).

CIS ince filmlerinin hazırlanmasında buhar biriktirme, sıçratma (sputtering), selenizasyon ve ek olarak da elektro-kimyasal biriktirme gibi birkaç yöntem kullanılmaktadır (Ohring, 1992). Murat Kaleli ve diğerleri termal buharlaştırma yöntemi kullanarak CIS filmlerini elde ederken (Murat Kaleli, 2017), Jingxia Yang ve diğerleri elektrokimyasal kaplama yöntemi kullanarak CIS filmlerini elde etmişlerdir (Yang, Jin, Li, Wang, \& Chai, 2009). Elektrokimyasal kaplamanın ucuz, basit, kontrol edilebilir olması, çevreye zararlı atık bırakmaması gibi özelliklerinden dolayı ince film üretmede alternatiftir (Sanjeeviraja \& Mahalıngam, 1992). Elektro-kimyasal biriktirme yönteminin iki çeşidi vardır; bunlar tek adımlı ve iki adımlı elektro-kimyasal biriktirme olarak adlandırılır. Bugüne kadar tek adımlı elektro-kimyasal biriktirme ile yüksek sıcaklık, vakum kazanı gibi yüksek maliyetli, zor parametreler kullanılmadan yüksek kalitede, geniş alanlı CIS ince filmleri üretilmiştir (A.E.-H.B. Kashyout, 2014; Liu et al., 2008; Sene, Ndiaye, Dieng, Mbow, \& Cong, 2009).

Rubrene (5,6,11,12 tetraphenylnaphthacene, $\left.\mathrm{C}_{42} \mathrm{H}_{28}\right)$, yük taşıyıcı mobilitesi, eksiton yayınım uzunluğu, foto-akım üretme verimliliği gibi özelliklere sahip olmasından dolayı gelecek vadeden küçük yapılı organik bir yarıiletkendir (Fumagalli, 2012). Rubrene 1960’dan beri elektrolüminesans ve kemilüminesans özellikleri ile göz önünde olan fakat keşfi 1900’lü yılların başlarına dayanan polycyclic aromatik hidrokarbondur (Bergantin, 2014). Rubrene, iki merkezi benzen $\left(\mathrm{C}_{6} \mathrm{H}_{6}\right)$ halkasının her iki tarafına bağlı fenil $\left(\mathrm{C}_{6} \mathrm{H}_{5}\right)$ tatracen (dört yapışık benzen halkası) temellinden oluşmuş olup, p-tipi yariiletken özelliği sergiler (Özdemir, 2013). Erime noktası $315^{\circ} \mathrm{C}$, molar ağırlığı 532,7 gr/mol olan kırmızı renkli bir bileşiktir (Fumagalli, 2012). Rubrenin en önemli uygulamaları fotovoltaik (PV) hücreler (Baris, Yuksel, Tugluoglu, \& Karadeniz, 2013), 1şık yayan diyodlar (LED) (Kim et al., 2007), organik alan etkili transistörler (OFET) ( Chan, 2007) ve organikinorganik heteroeklemlerdir (Uchida, Adachi, Koyama, \& Taniguchi, 1999).

Rubrene organik yarıiletken bileşiği Si (Barış, 2013) ve cam (Nitta et al., 2019) alt tabanlı malzemeler üzerine büyütülmüş ve yapısal, optiksel, elektriksel ve yüzeysel özellikleri incelenmiştir. Biz bu çalışmamızda organik rubrene yariiletkenini cam/ITO/CIS alt tabanı üzerine ilk kez termal buharlaştırma yöntemi ile kapladık ve yüzeysel ve optiksel özelliklerini inceledik. 
$\mathrm{Bu}$ çalışmada, cam/ITO/CIS/Rubrene heteroeklemlerinin düşük maliyet ile sentezlenmesi, yüzey ve optiksel özelliklerinin incelenmesi ve bunun sonucunda ise LED, fotosel, foto-sensör ve güneş pilleri gibi opto-elektronik devre elemanlarının yapımında kullanılabilecek bir alternatif malzeme olarak sunulması amaçlanmıştır.

\section{Materyal ve Metot}

CuInSe (CIS) bileşiğinin cam/ITO alt tabaka üzerine tek adımda elektro-kimyasal kaplama ile elde edilebilmesi için gerekli öncüler, alt tabakaların hazırlanması, öncü çözeltilerin hazırlanması ve deney parametrelerinin belirlenmesi olarak sıralanır. Bunun için $6 \mathrm{~cm}^{2}$ alanındaki cam/ITO alt tabakaları ilk önce ultra saf sudan geçirilmiştir. Daha sonra 250 ml’lik cam behere sabunlu su çözeltisi hazırlanmış, alt tabakalar bu çözelti içerisine yerleştirilmiş ve ultrasonik banyo içerisinde 10 dakika boyunca bekletilmiştir. Daha sonra alt tabakalar çözelti içerisinden çıkarılıp ultra saf su ile iyice durulanmıştır. Durulanan alt tabakalar ayrı bir cam beherde bulunan sıvı aseton içerisine yerleştirilmiş ve ultrasonik banyo içerisinde 10 dakika boyunca bekletilmiştir. Asetonla temizlik işlemi bittikten sonra alt tabakalar bir cam beherde bulunan propanol içerisine yerleştirilmiş ve yine ultrasonik banyo içerisinde 10 dakika boyunca bekletilmiştir. Propanol ile temizlik işlemi bittikten sonra alt tabakaların yüzeyleri azot gazı ile kurutulmuştur.

$\mathrm{Cu}$ kaynağı olarak 5 mM CuCl 2 (\%99,999), In kaynağ 1 olarak 5 mM $\operatorname{InCl}_{3}(\% 99,999)$, Se kaynağı olarak $10 \mathrm{mM} \mathrm{H}_{2} \mathrm{O}_{3} \mathrm{Se}$ (\%98) ve ayrıca elektrolit çözeltisinin iletkenliğini artırmak için ise 250 mM LiCl (\%99) ile 350 mM KCl (\%99) kullanılmıştır.

Tek adımda elektro-kimyasal kaplama reaksiyonu için tüm çözeltilerden 14 ml kullanılmak suretiyle elektrolit miktarı $70 \mathrm{ml}$ olacak şekilde ayarlanmıştır. Elektrolit çözeltisinin pH'ı $\mathrm{HCl}$ kullanılarak 1,9'a ayarlanmış olup, uygulama voltajı $\mathrm{Ag} / \mathrm{AgCl}$ referans elektroda karşı -0,7 V olarak belirlenmiştir. Karşıt elektrot olarak 1,0x1,5 cm boyutunda Pt plaka, referans elektrot olarak Ag/AgCl elektrodu ve çalışma elektrodu olarak $6 \mathrm{~cm}^{2}$ yüzey alanına sahip cam/ITO alttabakası kullanılmıştır. Reaksiyon oda sıcaklığında gerçekleştirilmiş ve reaksiyon süresi 20 dakika olarak belirlenmiştir. Reaksiyon süresince reaksiyonun gerçekleştiği hücre içerisinden 0,1 bar $\mathrm{N}_{2}$ gazı geçirilmiştir.

Elektro-kimyasal kaplama işleminden sonra rubrene ince filmlerinin oluşturulması aşaması için cam/ITO/CIS yapıları, bir termal buharlaştırma sistemine yerleştirilmiştir. Toz halindeki rubrenenin termal buharlaştırma ile kaplama işleminde molibden (Mo) pota kullanılmıştır. Mo pota propanol ile temizlenmiş ve termal buharlaştırma işlemine başlamadan önce vakum ortamında 1sıtılarak üzerinde bulunan kirlilikler uzaklaştırılmıştır. Pota ile alttabakalar arası mesafe yaklaşık $10 \mathrm{~cm}$ olarak belirlenmiştir. Kaplama oda sıcaklığında ve $2,5 \times 10^{-6}$ torr basınç altında gerçekleşmiştir. 
AFM analizi hava ortamında, dinamik modda, Tap 190Al-G tipi cantilever kullanılarak yapılmıştır. UV-Vis analizide hava ve karanlık ortamda, oda sıcaklığında yapılmıştır.

Elektro-kimyasal kaplama işlemleri için Autolab marka PGSTAT128N model elektrokimyasal potentiostat/galvanostat cihazı, termal buharlaştırma ile kaplama için ise Vaksis marka PVDMT/2M2T termal buharlaştırma ince film kaplama sistemi kullanılmıştır.

\section{Bulgular ve Tartışma}

$\mathrm{Bu}$ çalışmada elektro-kimyasal kaplama yöntemi ile elde edilen CIS inorganik yarıiletken bileşiğinin üzerine rubrene organik yarıiletken bileşikleri termal buharlaştırma yöntemiyle kaplanmıştır. Üretilen CIS yapılarının yüzey ve optiksel özellikleri incelenmiştir. Daha sonra inorganik CIS bileşiklerinin üzerine organik rubrene ince filmlerinin kaplanmasının ardından heteroeklemlerin yüzey ve optiksel özellikleri yeniden incelenmiştir.

Filmlerin kalınlıkları maskeleme yöntemi kullanılarak AFM cihazı ile belirlenmiştir. Kaplama yapılmadan önce alttabaka teflon bant ile maskelenmiş, kaplama yapıldıktan sonra teflon bant sökülmüştür. Böylece kaplanan yüzey ile kaplanmayan yüzey arasında bariz bir kalınlık farkı oluştuğu gözlenmiş ve AFM kullanarak üretilen ince filmlerin kalınlıkları belirlemişlerdir (Tae Hun, 2001). Cam/ITO üzerine büyütülen CIS ince filmlerinin kalınlığı 922 nm ve rubrene kalınlığı ise 650 nm olarak belirlenmiştir.

\subsection{Atomik Kuvvet Mikroskobu (AFM) Analizi}

Cam/ITO/CIS ince filminin 25x25 $\mu \mathrm{m}$ tarama alanında ortalama pürüzlülük değeri 231,6 nm olarak belirlenmiştir. Şekil 1'de cam/ITO/CIS ince filminin iki ve üç boyutlu AFM görüntüleri verilmiştir.

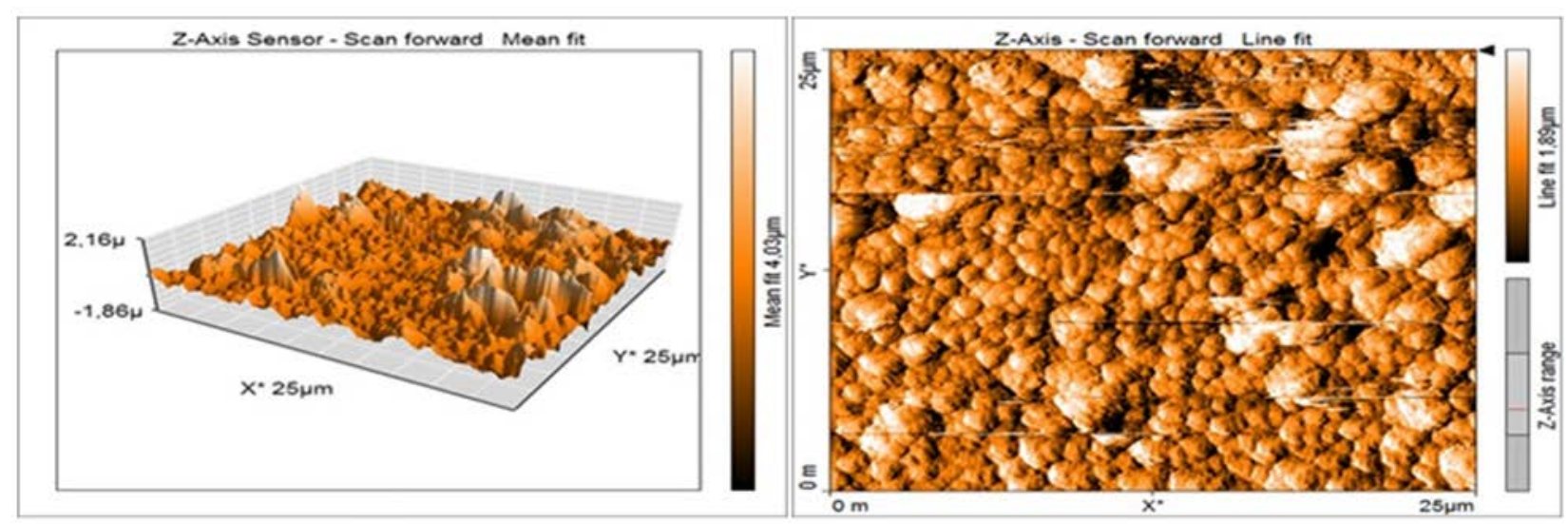

(a)

(b)

Şekil 1. Cam/ITO/CIS yapılarının AFM görüntüleri: a) 3 boyutlu ve b) 2 boyutlu. 
Cam/ITO/CIS/rubrene yapılarındaki rubrene ince filminin 25x25 $\mu \mathrm{m}$ tarama alanında ortalama pürüzlülük değeri 182,82 nm olarak belirlenmiştir. Şekil 2'de cam/ITO/CIS/rubrene ince filminin iki ve üç boyutlu AFM görüntüleri verilmiştir.

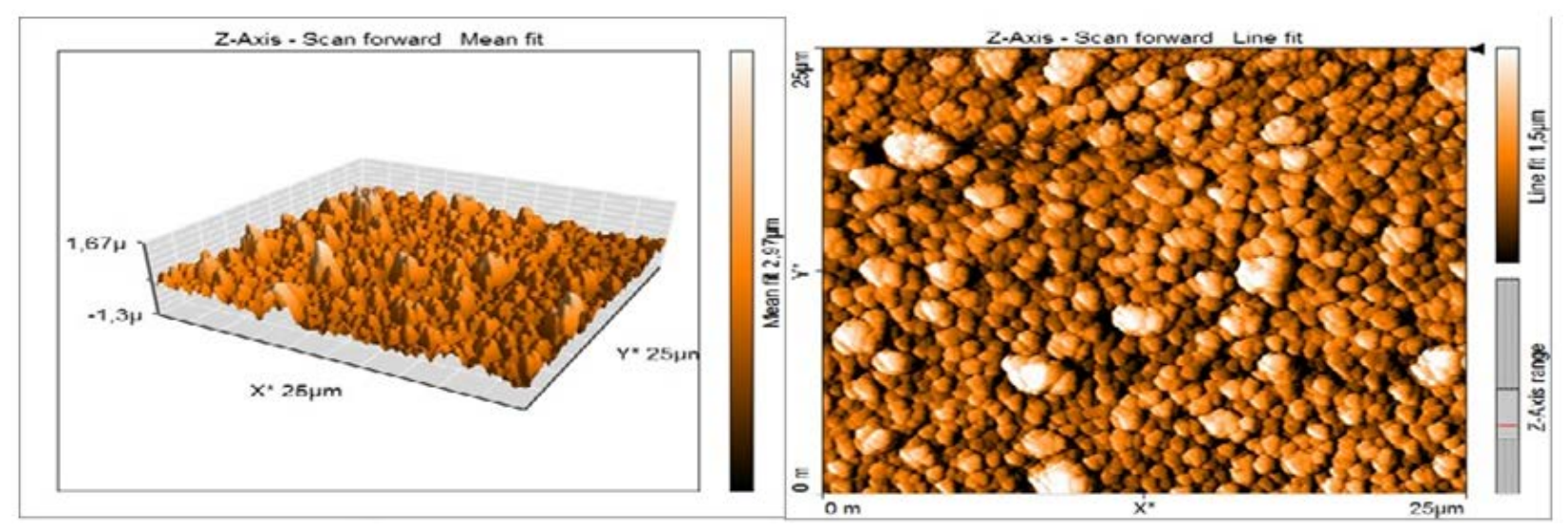

(a)

(b)

Şekil 2. Cam/ITO/CIS/rubrene yapılarının AFM görüntüleri: a) 3 boyutlu b) 2 boyutlu

\subsection{Optiksel Özellikler}

Temel soğurma spektrumu yasak bant aralığının belirlenmesinde en çok kullanılan yöntemlerden biridir. Soğurma katsayısı ile yasak bant arasındaki bağıntı denklem 1'de verilmektedir. Bu denklem;

$$
\alpha(h v) \approx\left(h v-E_{g}\right)^{n}
$$

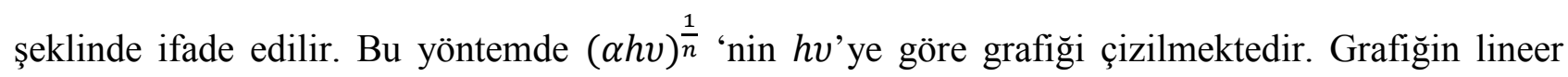
kısmına karşılık gelen doğrunun $h v$ ekseninin kestiği noktanın enerji değeri o materyalin yasak bant aralığını verir (Ilıcan, 2005). Burada n değeri, CIS (Frontini \& Vazquez, 2010) ve rubrene (Chen et al., 2015) yapısının doğrudan bant aralığına sahip olduğu için 1⁄2’ dir.

Şekil 3’te cam/ITO üzerine büyütülen CIS ince filmlerinin dalga boyuna bağlı optik soğurma ve optik geçirgenlik grafikleri verilmiştir. Şekil 4'de cam/ITO üzerine büyütülen CIS ince filmlerinin yasak enerji bant aralığı eğrisi verilmiştir. Cam/ITO/CIS filminin 700 nm’de optik geçirgenliği \%0,22, 400 nm'de optik geçirgenliği \%0,07, yasak enerji aralığının değeri ise 1,42 eV olarak belirlenmiştir. 


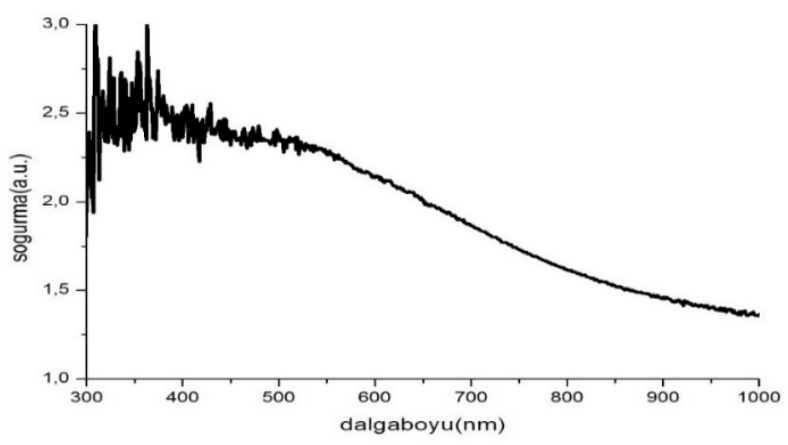

(a)

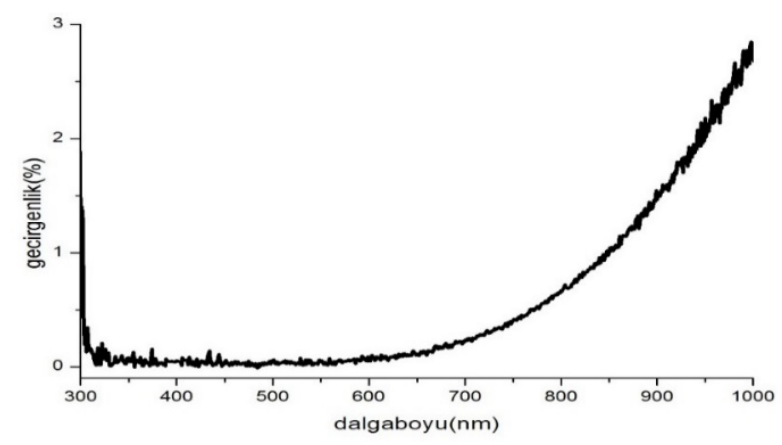

(b)

Şekil 3. Cam/ITO/CIS yapılarının dalga boyuna bağlı a) soğurma, b) geçirgenlik eğrileri.

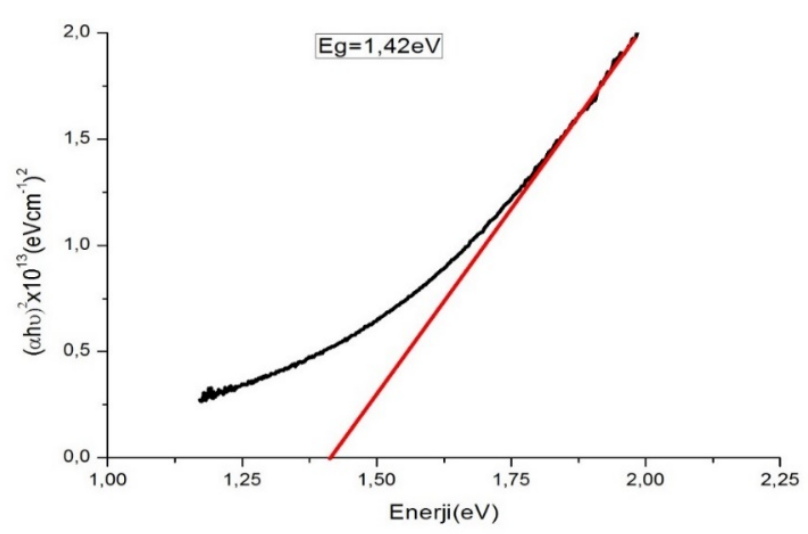

Şekil 4. Cam/ITO/CIS yapısının yasak enerji bant aralığı.

Şekil 5'te cam/ITO/CIS/rubrene ince filmlerinin dalga boyuna bağlı optik soğurma ve optik geçirgenlik grafikleri verilmiştir. Şekil 6'da ise cam/ITO/CIS/rubrene ince filmlerinin yasak enerji bant aralığg eğrisi verilmiştir. Cam/ITO/CIS/Rubrene filminin 700 nm'de optik geçirgenliği \%0,29, $400 \mathrm{~nm}$ 'de optik geçirgenliği \%0,16 ve yasak enerji bant aralı̆̆ının değeri ise 2,07 eV olarak belirlenmiştir. 


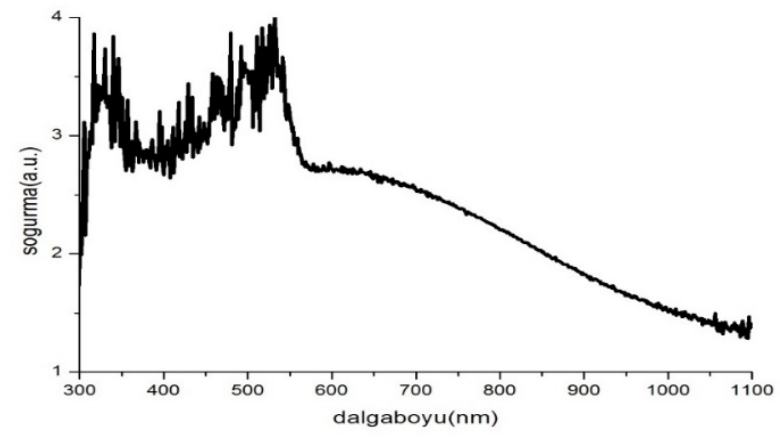

(a)

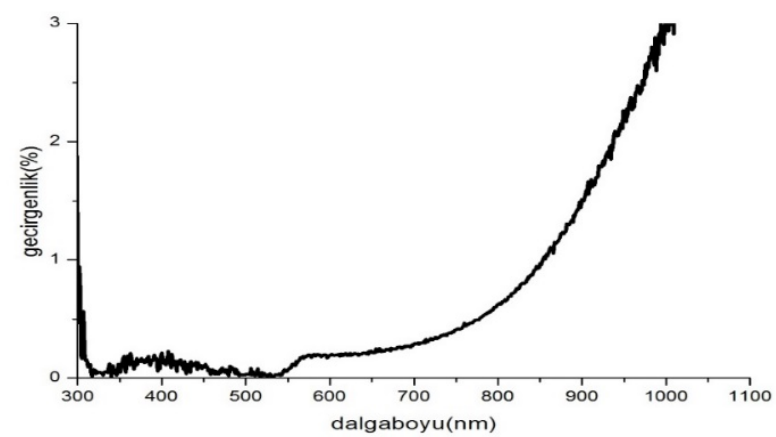

(b)

Şekil 5. Cam/ITO/CIS/rubrene yapılarının dalga boyuna bağlı a) soğurma, b) geçirgenlik eğrileri.

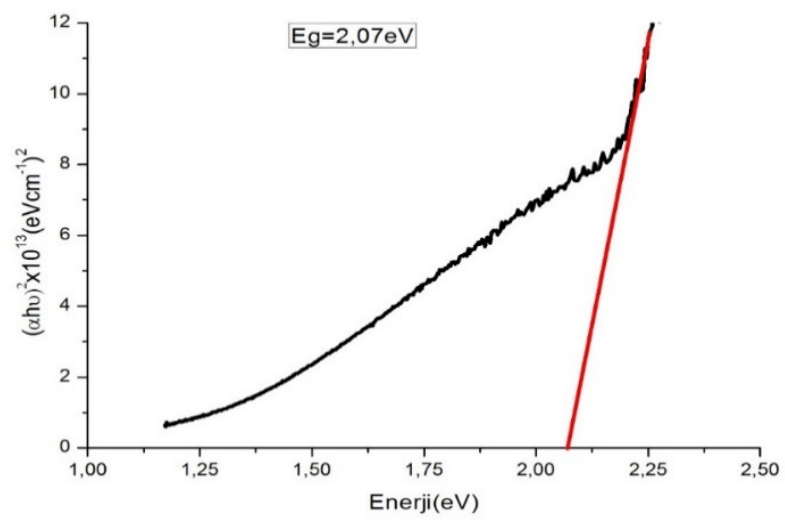

Şekil 6. Cam/ITO/CIS/rubrene yapısının yasak enerji bant aralı̆̆ı.

\section{Sonuçlar ve Öneriler}

$\mathrm{Bu}$ çalışmada, cam/ITO/CIS/Rubrene heteroeklemlerinin düşük maliyet ile sentezlenmesi, yüzey ve optiksel özelliklerinin incelenmesi ve bunun sonucunda ise LED, fotosel, foto-sensör ve 
güneş pilleri gibi opto-elektronik devre elemanlarının yapımında kullanılabilecek bir alternatif malzeme olarak sunulması amaçlanmıştır.

İnorganik yariiletken CuInSe (CIS) ince filmi cam/ITO alttabakası üzerine tek adımda elektro-kimyasal kaplama yöntemi ile kaplanmış, daha sonra elde edilen cam/ITO/CIS yapısı üzerine rubrene $\left(\mathrm{C}_{42} \mathrm{H}_{28}\right)$ organik yarıiletkeni termal buharlaştırma yöntemi kullanılarak başarılı bir şekilde büyütülmüştür. AFM analizinde cam/ITO/CIS ince filminin 25x25 $\mu \mathrm{m}$ tarama alanında ortalama pürüzlülük değeri 231,6 nm ve olarak belirlenmiştir. Cam/ITO/CIS/rubrene ince filminin $25 \times 25 \mu \mathrm{m}$ tarama alanında ortalama pürüzlülük değeri 182,82 nm olarak belirlenmiştir. Cam/ITO/CIS filminin 700 nm'de optik geçirgenliği \%0,22, 400 nm'de optik geçirgenliği \%0,07, yasak enerji bant aralığının değeri ise $1,42 \mathrm{eV}$ olarak belirlenmiştir. Cam/ITO/CIS/Rubrene filminin 700 nm'de optik geçirgenliği \%0,29, 400 nm'de optik geçirgenliği \%0,16, yasak enerji aralığının değeri ise 2,07 eV olarak belirlenmiştir. Literatür taramasında S. Rozeveld ve diğerleri CIS filmlerinin pürüzlülük değerlerini yaklaşık $100 \mathrm{~nm}$ olarak hesaplamışlardır (Rozeveld, Reinhardt, Bykov, \& Wall, 2018). Yasak enerji aralığının belirlenmesinde film kalınlığı, filmin elementel dağılımı, sıcaklık gibi parametreler önemli bir yere sahiptir (Ünal, 2013). İdris Candan ve diğerleri CIS ince filminin yasak enerji aralığını yaklaşık 1,3 eV olarak hesaplamışlardır (Candan \& Güllü, 20019). Bahzad B. ve diğerleri cam üzerine büyüttükleri rubrene ince filminin yasak enerji aralığını 2,3 eV olarak hesaplamışlardır (Barış et al., 2014). Rubrene organik yarıiletken bileşiği ilk kez cam/ITO/CIS alt tabanı üzerine büyütüldüğü için literatürde bu heteroekleme ait yüzey pürüzlülüğü değerine rastlanamamaktadır fakat Michael A. ve diğerleri kristal ince film rubrenenin $5 \mu \mathrm{mx} 5 \mu \mathrm{m}$ tarama alanında yüzey pürüzlülüğünü 100nm olarak hesaplamışlardır (Fusella et al.).

Cam/ITO/CIS ve cam/ITO/CIS/Rubrene filminin görünür bölgedeki geçirgenlik değerleri oldukça düşüktür ve bu üzerine gelen 1şığın büyük kısmını soğurduğu anlamına gelir ki bu optoelektronik uygulamalarda önemli ve aranan bir özelliktir. Optik soğurmalar her iki filmde de görünür bölgede gerçekleşmiştir. Cam/ITO/CIS ince filmi geniş bir aralıkta soğurma gerçekleştirmiştir, cam/ITO/CIS/Rubrene ince filmi ise yaklaşık 550nm bölgesinde keskin bir soğurma piki vermiştir. Behzad B. ve diğerleri cam üzerine büyüttükleri rubrene ince filmlerinin görünür bölge sınırlarında (400-700nm) geçirgenlik değerlerini \%80-85 olarak belirlemişlerdir (Barış et al., 2014). Yapmış olduğumuz çalışmada cam/ITO/CIS/Rubrene ince filminin daha iyi soğurma özelliği gösterdiği görülmektedir. Çalışmasını yapıp daha yayımlamadığımız cam/ITO/CIS/Coronene ince filmine kıyasla cam/ITO/CIS/Rubrene ince filmi daha iyi soğurma özelliğine sahip olduğu görülmüştür.

Yapmış olduğumuz bu çalışma Türkiye Cumhuriyeti İnönü Üniversitesi Fen Bilimleri Enstitüsü Fizik Anabilim Dalında ITO CAM ÜZERINE BÜYÜTÜLEN CIGS/CORONENE, CIS/CORONENE, InSe/CORONENE, CIGS/RUBRENE, CIS/RUBRENE, InSe/RUBRENE 


\section{HETEROEKLEMLERINN YAPISAL, OPTIKK VE ELEKTRİKSEL ÖZELLİKLERİNIN}

BELİRLENMESİ başlıklı doktora tezinden üretilmiştir.

\section{Teşekkür}

Hem deneysel süreçte kullanmış olduğumuz elektrokimyasal empedans spektroskopisi sistemi ve termal buharlaştırma ince film kaplama sistemi hem de analiz sürecinde kullanmış olduğumuz AFM ve UV-VIS cihazlarını bünyesinde bulunduran ve kullanımımıza sunan GÜRÜMLAB kurumuna teşekkür ederim.

\section{Kaynaklar}

A.E.-H.B. Kashyout, E.-Z. A., T. Meaz, M. Nabil , M. Amer. (2014). (One-step) electrochemical deposition and characterization of CuInSe2 thin films. Alexandria Engineering Journal, 53, 731-736.

Baris, B., Yuksel, O. F., Tugluoglu, N., \& Karadeniz, S. (2013). Double barrier heights in 5,6,11,12-tetraphenylnaphthacene (rubrene) based organic Schottky diode. Synthetic Metals, 180, 38-42. doi:10.1016/j.synthmet.2013.07.029

Barış, B. (2013). Frequency dependent capacitance and conductance properties of Schottky diode based on rubrene organic semiconductor. Physica B: Condensed Matter, 426, 132-136. doi:https://doi.org/10.1016/j.physb.2013.06.016

Barış, B., Özdemir, H. G., Tuğluoğlu, N., Karadeniz, S., Yüksel, Ö. F., \& Kişnişci, Z. (2014). Optical dispersion and dielectric properties of rubrene organic semiconductor thin film. Journal of Materials Science: Materials in Electronics, 25(8), 3586-3593. doi:10.1007/s10854-014-2060-6.

Bari, R.H., L. A. P., Patil, P.P., (2006). Studies on chemically deposited nonstoichiometric thin films of CuInSe2-a highly promising material for photosensors. Sensors \& Transducers Journal, 69(7).

Bergantin, S. (2014). Organic semiconductor rubrene: crystal chemistry of derivatives and highpressure polymorphism. (Doctorate). UNIVERSITÁ DEGLI STUDI DI MILANOBICOCCA,

C. Sanjeeviraja, \& Mahalıngam, T. (1992). Structural and optical properties of electrodeposited indium selenide thin films. Journal of Material Science Letters, 11, 525-526.

Candan, İ., \& Güllü, H. H. (20019). Comparative Study on The Properties of CuInSe2 and CuGaSe2 Thin Films. European Journal of Science and Technology, 15, 77-85.

Chan, M. Y., S. L. L., Fung, M. K., Leea, C. S., and Lee, S. T., (2007). Doping-induced efficiency enhancement in organic photovoltaic devices. Applied Physics Letters, 90, 023504-023506.

Chen, L., Deng, J. X., Kong, L., Cui, M., Chen, R. G., \& Zhang, Z. J. (2015). Optical properties of rubrene thin film prepared by thermal evaporation. Chinese Physics B, 24(4). doi:10.1088/1674-1056/24/4/047801

Frontini, M. A., \& Vazquez, M. (2010). Electrodeposition of CuInSe2 in citrate-containing electrolytes. Journal of Materials Science, 45(11), 2995-3000. doi:10.1007/s10853-0104300-3

Fumagalli, E. M. (2012). Growth and physical properties of crystalline rubrene. (doctorate). Università degli Studi di Milano-Bicocca, 
Fusella, M. A., Schreiber, F., Abbasi, K., Kim, J. J., Briseno, A. L., \& Rand, B. P. Homoepitaxy of Crystalline Rubrene Thin Films Retrieved from

Kim, K., Kim, M. K., Kang, H. S., Cho, M. Y., Joo, J., Kim, J. H., . . Choi, D. H. (2007). New growth method of rubrene single crystal for organic field-effect transistor. Synthetic Metals, 157(10-12), 481-484. doi:10.1016/j.synthmet.2007.05.013

Liu, F. Y., Lu, Y., Zhang, Z. A., Lai, Y. Q., Li, J., \& Liu, Y. X. (2008). Pulse-plating electrodeposition and annealing treatment of CuInSe2 films. Transactions of Nonferrous Metals Society of China, 18(4), 884-889. doi:10.1016/s1003-6326(08)60153-3

Liu, F. Y., Zhang, Z. A., Lai, Y. Q., Li, J., \& Liu, Y. X. (2009). Composition and Morphology of Electrodeposited CuInSe2 Precursor Films. Journal of Materials Science \& Technology, 25(2), 242-246. Retrieved from < Go to ISI $>$ ://WOS:000264990700021

Kaleli, M., C. A. Y., Koç, M., Akyürekli, S., Bayram, A., B., (2017). Termal Buharlaştırma Yöntemiyle Hazırlanan Ga Katkılı CuInSe2 İnce Filmlerin Yapısal Özelliklerinin İncelenmesi. Süleyman Demirel Üniversitesi Fen Edebiyat Fakültesi Fen Dergisi, 12, 19-32.

Nitta, J., Miwa, K., Komiya, N., Annese, E., Fujii, J., Ono, S., \& Sakamoto, K. (2019). The actual electronic band structure of a rubrene single crystal. Sci Rep, 9(1), 9645. doi:10.1038/s41598-019-46080-4

Ohrıng, M. (1992). The Materials Science of Thin Films. Boston: Academic Press.

Özdemir, H. G. (2013). Spin Kaplama Yöntemiyle Rubrene Ince Filmlerinin Hazırlanması Ve Optiksel Özelliklerinin Incelenmesi. (Yüksek Lisans). Giresun Üniversitesi,

Rozeveld, S., Reinhardt, C., Bykov, E., \& Wall, A. (2018). Measurement of Grain Boundary Properties in $\mathrm{Cu}(\mathrm{ln}, \mathrm{Ga}) \mathrm{Se} 2$ Thin Films. Microscopy Today, 26(3), 32-39. doi:10.1017/s1551929518000457

Saliha ILICAN, Y. Ç., Müjdat ÇAGLAR. (2005). CdZnS ve Zn O YARIİLETKEN FiLMLERININ YASAK ENERJİ ARALIKLARI SAÜ Fen Bilimleri Enstitüsü Dergisi 9.

Sene, C., Ndiaye, B., Dieng, M., Mbow, B., \& Cong, H. N. (2009). CuIn (Se, S)(2) based photovoltaic cells from one-step electrodeposition. International Journal of the Physical Sciences, 4(10), 562-570. Retrieved from <Go to ISI $>$ ://WOS:000270305900004

Tae Hun, K., Hyuck In, Kwon Jong Duk, Lee Byung-Gook Park. (2001). Thickness measurements of ultra-thin films using AFM. Paper presented at the Digest of Papers. Microprocesses and Nanotechnology 2001. 2001 International Microprocesses and Nanotechnology Conference (IEEE Cat. No.01EX468), japan.

Uchida, M., Adachi, C., Koyama, T., \& Taniguchi, Y. (1999). Charge carrier trapping effect by luminescent dopant molecules in single-layer organic light emitting diodes. Journal of Applied Physics, 86(3), 1680-1687. doi:10.1063/1.370947

Ünal, F. (2013). InSe İnce Filmlerinin Farklı Alt Tabanlar Üzerinde Büyütülmesi Ve Optik, Yapısal, Fotoelektirik Özelliklerinin Araştırılması. (Yüksek Lisans). Kafkas Üniversitesi, Kars.

Yang, J., Jin, Z., Li, C., Wang, W., \& Chai, Y. (2009). Electrodeposition of CuInSe2 films by an alternating double-potentiostatic method using nearly neutral electrolytes. Electrochemistry Communications, 11(3), 711-714. doi:10.1016/j.elecom.2008.12.062 